\title{
Production of 1,3-Propanediol by Clostridium butyricum VPI 3266 in continuous cultures with high yield and productivity
}

\begin{abstract}
The effects of dilution rate and substrate feed concentration on continuous glycerol fermentation by Clostridium butyricum VPI 3266, a natural 1,3-propanediol producer, were evaluated in this work. A high and constant 1,3-propanediol yield (around $0.65 \mathrm{~mol} /$ $\mathrm{mol}$ ), close to the theoretical value, was obtained irrespective of substrate feed concentration or dilution rate. Improvement of 1,3-propanediol volumetric productivity was achieved by increasing the dilution rate, at a fixed feed substrate concentration of 30,60 or $70 \mathrm{~g}^{-1}$. Higher 1,3-propanediol final concentrations and volumetric productivities were also obtained when glycerol feed concentration was increased from 30 to $60 \mathrm{~g} \mathrm{l}^{-1}$, at $D=0.05-0.3 \mathrm{~h}^{-1}$, and from $60-70 \mathrm{~g} \mathrm{l}^{-1}$, at $D=0.05$ and $0.1 \mathrm{~h}^{-1} \cdot 30 \mathrm{~g} \mathrm{l}^{-1}$ of 1,3-propanediol and the highest reported value of productivity, $10.3 \mathrm{~g} \mathrm{l}^{-1} \mathrm{~h}^{-1}$, was achieved at $D=0.30 \mathrm{~h}^{-1}$ and $60 \mathrm{~g} \mathrm{l}^{-1}$ of feed glycerol. A switch to an acetate/butyrate ratio higher than one was observed for $60 \mathrm{~g} \mathrm{l}^{-1}$ of feed glycerol and a dilution rate higher than $0.10 \mathrm{~h}^{-1}$; moreover, at $D=0.30 \mathrm{~h}^{-1} 3$-hydroxypropionaldehyde accumulation was observed for the first time in the fermentation broth of C. butyricum.
\end{abstract}

Keywords Clostridium butyricum · 1,3-propanediol · Continuous cultures $\cdot 3$-hydroxypropionaldehyde

\section{Introduction}

1,3-propanediol is a versatile degradable intermediate compound for the synthesis of heterocycles and a monomer for the production of polymers, such as

M. González-Pajuelo · J. C. Andrade · I. Vasconcelos ( $\square)$ Escola Superior de Biotecnologia,

Universidade Católica Portuguesa,

Rua Dr. António Bernardino de Almeida, 4200 Porto, Portugal

E-mail: ivasc@esb.ucp.pt

Tel.: + 351-225-580049

Fax: +351-225-090351 polyesters and polyurethanes. The classic route to produce this monomer is the chemical process from acrolein, a very harmful reagent. As an alternative, it has been shown that some bacteria are able to produce 1,3-propanediol from glycerol $[2,7-9,15,16]$. The recent development of PTT, a new polyester based on 1,3-propanediol and terephtalic acid, has increased the number of studies on microbial conversion of glycerol to 1,3-propanediol [3]. Yield, final product concentration and volumetric productivity are the main issues for the feasibility of an industrial production process. A high final product concentration in the effluent turns the down-stream separation process less expensive and, at the same time, contributes to achieve a high volumetric productivity [3]. Clostridium butyricum VPI 3266 was described as probably the best natural 1,3-propanediol producer since, unlike other microorganisms, production of 1,3-propanediol by this strain is not a $B_{12}$-vitamin dependent process, which is clearly an economical advantage for an industrial application [13]. Furthermore, production of 1,3-propanediol by this strain using a synthetic medium and low-price raw glycerol has been recently reported [4]. Glycerol is metabolised by $C$. butyricum following two pathways. One pathway leads to glycerol oxidation to dihydroxyacetone (DHA) by a NAD ${ }^{+}$-dependent glycerol dehydrogenase, followed by DHA phosphorilation to DHA-phosphate (DHAP) by a DHA kinase; DHAP enters the glycolytic pathway. In the other pathway glycerol is dehydrated to 3-hydroxipropionaldehyde (3-HPA) via a glycerol dehydratase; 3 -HPA is then reduced to 1,3-propanediol by a 1,3-propanediol dehydrogenase with NADH consumption, leading to a theoretical yield of $0.70 \mathrm{~mol} / \mathrm{mol}$ in conditions of no butyrate and no $\mathrm{H}_{2}$ formation [2, 3, 18].

Since an industrial utilisation of $C$. butyricum VPI 3266 may be suggested, continuous glycerol fermentations of this strain have been carried out in the present work in order to increase 1,3-propanediol concentration and productivity by manipulating dilution rate and glycerol feed concentration. 


\section{Materials and methods}

Organism

Clostridium butyricum VPI 3266 (Virginia Polytechnic Institute Culture Collection, Blacksburg, Va.) was maintained in the synthetic medium described below, in spore form, at $-20^{\circ} \mathrm{C}$. This strain is available from other culture collections as C. butyricum NCIMB 7423 (National Collections of Industrial and Marine Bacteria Ltd., Aberdeen, Scotland, United Kingdom) and $C$. butyricum CECT 361 (Colección Española de Cultivos Tipo; Universitat de Valencia, Valencia, Spain).

\section{Culture media}

The synthetic medium used in the experiments contained per litre of deionized water: glycerol, $30-80 \mathrm{~g} ; \mathrm{KH}_{2} \mathrm{PO}_{4}$, $0.5 \mathrm{~g} ; \mathrm{K}_{2} \mathrm{HPO}_{4}, 0.5 \mathrm{~g} ; \mathrm{MgSO}_{4} .7 \mathrm{H}_{2} \mathrm{O}, 0.2 \mathrm{~g} ; \mathrm{CoCl}_{2} .6-$ $\mathrm{H}_{2} \mathrm{O}, 0.01 \mathrm{~g} ; \mathrm{FeSO}_{4} .7 \mathrm{H}_{2} \mathrm{O}, 0.01 \mathrm{~g}$; biotin, $0.04 \mathrm{mg}$; $p$-aminobenzoic acid, $8 \mathrm{mg}$; acetic acid, $2 \mathrm{~g}$. The medium $\mathrm{pH}$ was adjusted to 6.5 with $6 \mathrm{~N} \mathrm{NH}_{4} \mathrm{OH}$. The feed medium for continuous cultures was the synthetic medium described above, without acetic acid, and with $0.028 \mathrm{~g} \mathrm{l}^{-1}$ of $\mathrm{FeSO}_{4} .7 \mathrm{H}_{2} \mathrm{O}$ (instead of $0.01 \mathrm{~g} \mathrm{l}^{-1}$ ), $1.5 \mathrm{~g} \mathrm{l}^{-1}$ of $\mathrm{NH}_{4} \mathrm{Cl}$ and $1 \mathrm{ml}$ of $\mathrm{H}_{2} \mathrm{SO}_{4} 17.4 \mathrm{M}$; medium $\mathrm{pH}$ was not adjusted in this case.

\section{Continuous cultures conditions}

Continuous cultures were performed in a 2-1 bioreactor (Biostat MD; Braun, Melsungen, Germany), with a working volume of $1,250 \mathrm{ml}$, and in a $400 \mathrm{ml}$ glass bioreactor, with a working volume of $300 \mathrm{ml}$. The culture was stirred at $200 \mathrm{rpm}$, temperature was set to $35^{\circ} \mathrm{C}$ and $\mathrm{pH}$ was maintained constant by automatic addition of $6 \mathrm{~N} \mathrm{NH}_{4} \mathrm{OH}$. To create anaerobic conditions, the sterilised medium in the vessel was flushed with sterile $\mathrm{O}_{2}$-free nitrogen until room temperature was attained. A growing culture taken at the early exponential growth phase was used as inoculum $(10 \% \mathrm{v} / \mathrm{v})$. The culture was first grown batchwise and continuous feeding was started once the exponential growth phase was reached. After sterilisation, the feed medium was sparged with sterile $\mathrm{O}_{2}$-free nitrogen, until room temperature was reached. During the experiments, the feed medium was maintained under nitrogen at $30 \mathrm{mbar}$, to avoid $\mathrm{O}_{2}$ entry. All tubing was made of butyl rubber and the bioreactor gas outlet was protected with a pyrogallol arrangement [17].

\section{Analytical procedures}

Cell concentration was measured turbidometrically, at $620 \mathrm{~nm}$, and correlated with cell dry weight determined directly. Glycerol, 1,3-propanediol, ethanol and acetic, butyric and lactic acid concentrations were determined by HPLC (System Gold; Beckman, Fullerton, CA, USA). Separation was performed on a Biorad Aminex HPX-87H column $(300 \times 7.8 \mathrm{~mm}$; Bio-Rad, Richmond, CA, USA) and detection was achieved by refractive index. Operating conditions were as follows: mobile phase, sulphuric acid $0.5 \mathrm{mM}$; flow rate, $0.5 \mathrm{ml} / \mathrm{min}$; temperature, $30^{\circ} \mathrm{C}$. A qualitative HPLC analysis of 3-hydroxypropionaldehyde in fermentation broth was also performed in the conditions described. As 3-HPA is not commercially available, it was chemically synthesised following the method described by Hall and Stern [5].

1,3-propanediol volumetric productivity $\left(Q_{1,3 \text {-pro- }}\right.$ panediol) and specific 1,3-propanediol formation or glyc-

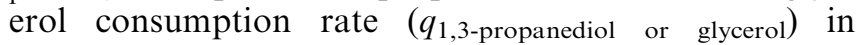
chemostat cultures were calculated as $Q_{1,3 \text {-propanediol }}=$ $C_{1,3 \text {-propanediol }} \times \mathrm{D}$ and $q_{1,3 \text {-propanediol or glycerol }}=C_{1,3-}$ propanediol or glycerol $\times \mathrm{D} / \mathrm{X}$ respectively, where $\mathrm{C}_{1,3 \text {-pro- }}$ panediol is the 1,3-propanediol mass concentration, $C_{\text {glycerol }}$ is the consumed glycerol mass concentration, $D$ is the dilution rate of the chemostat and $X$ is the cell mass concentration.

\section{Results}

Effect of dilution rate on continuous 1,3-propanediol production

Dilution rate was increased from 0.05 to $0.50 \mathrm{~h}^{-1}$ in chemostat cultures of $C$ butyricum VPI 3266, with a constant glycerol feed of $30 \mathrm{~g} \mathrm{l}^{-1}$. 1,3-propanediol was the major fermentation end-product, attaining $15 \mathrm{~g}^{-1}$ (Fig. 1a), and acetate and butyrate were the main byproducts. No ethanol or lactate, other possible fermentation products, were synthesised. Residual glycerol exceeded $1 \mathrm{~g} \mathrm{l}^{-1}$ only when dilution rate increased above $0.3 \mathrm{~h}^{-1}$ (Fig. 1b). At higher dilution rate of $0.5 \mathrm{~h}^{-1}$, residual glycerol had reached $12.5 \mathrm{~g}^{-1}$ and severe decreases in biomass $\left(0.2 \mathrm{~g}^{-1}\right)$ and 1,3-propanediol $\left(8.1 \mathrm{~g}^{-1}\right)$ were observed (data not shown). Up to a dilution rate of $0.40 \mathrm{~h}^{-1}, 1,3$-propanediol concentration was constant, leading to an increase in the volumetric productivity, with a maximum value of $5.5 \mathrm{~g} \mathrm{l}^{-1} \mathrm{~h}^{-1}$ (Fig. 2). For every $D$ value, conversion of glycerol into 1,3-propanediol was between 0.60 and $0.68 \mathrm{~mol} 1,3-$ propanediol/mol glycerol consumed (Fig. 1a), indicating that the carbon flux through the 1,3-propanediol pathway is under a strong regulation.

Effect of glycerol feed concentration on continuous 1,3-propanediol production

The effect of glycerol feed concentration on the fermentation pattern of C. butyricum VPI 3266 in chemostat was also studied. Feed glycerol concentration varied from 30 to $70 \mathrm{~g} \mathrm{l}^{-1}$ at different dilution rates $(0.05$ 
Fig. 1 Influence of glycerol feed concentration and dilution rate on a-1,3-propanediol molar yield (solid symbols) and 1,3-propanediol concentration (open symbols) and on bbiomass concentration (solid symbols) and residual glycerol (open symbols) in continuous cultures of $C$. butyricum VPI $3266\left(\mathrm{pH} 6.5,35^{\circ} \mathrm{C}\right)$. circle, filled circle $30 \mathrm{~g}^{-1}$ of feed glycerol; square, filled square $60 \mathrm{~g} \mathrm{l}^{-1}$ of feed glycerol; inverted triangle, closed inverted triangle $70 \mathrm{~g}^{-1}$ of feed glycerol. Vertical bars represent standard deviation values
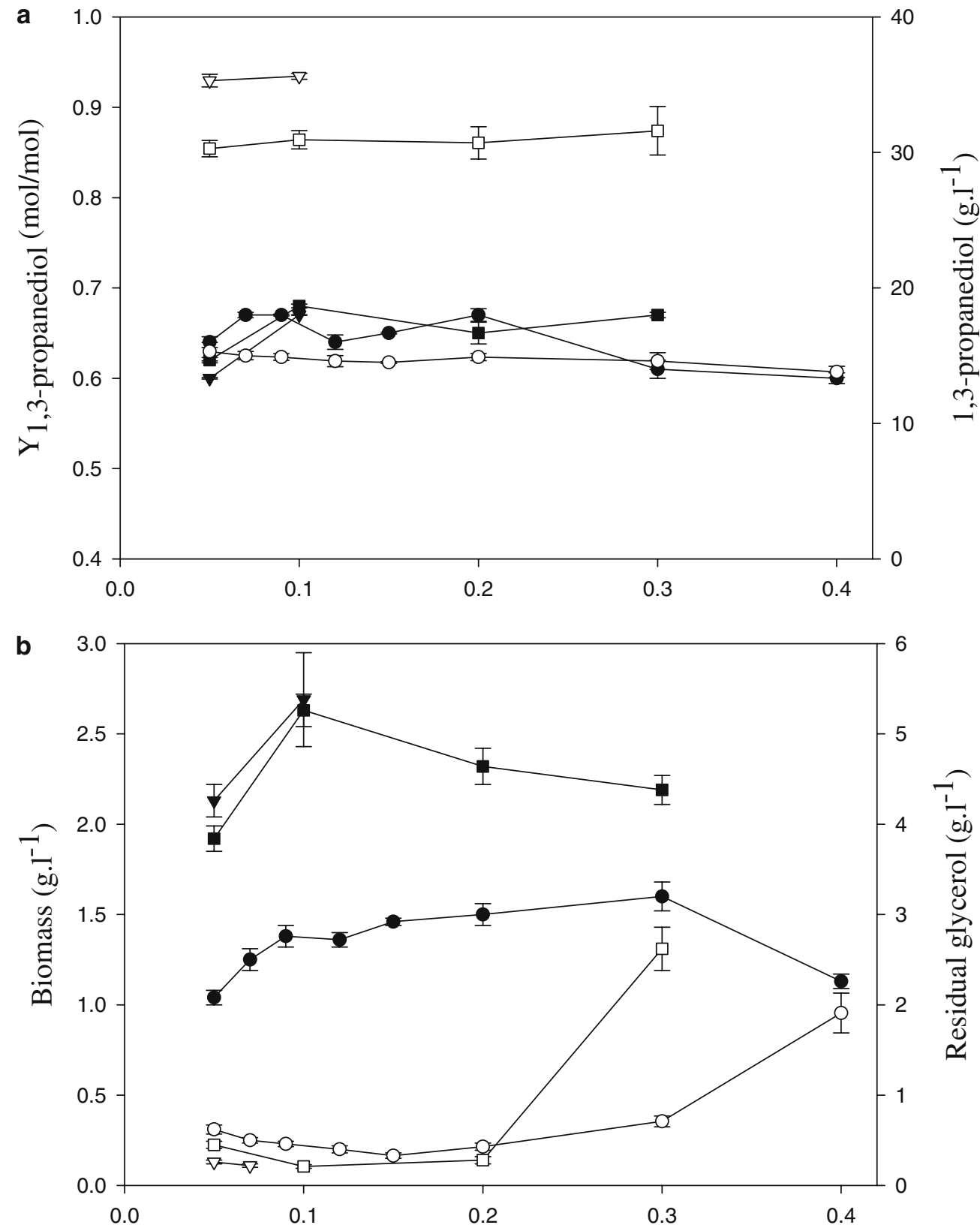

Dilution rate $\left(\mathrm{h}^{-1}\right)$
$0.30 \mathrm{~h}^{-1}$ ). However, when $70 \mathrm{~g} \mathrm{l}^{-1}$ of glycerol were fed at a dilution rate of $0.20 \mathrm{~h}^{-1}$ washout of the reactor occurred.

For every dilution rate, an increase in glycerol feed concentration led to an increase in 1,3-propanediol concentration, which achieved $35 \mathrm{~g}^{-1}$ for $70 \mathrm{~g} \mathrm{l}^{-1}$ of feed glycerol, and $30 \mathrm{~g}^{-1}$ for $60 \mathrm{~g} \mathrm{l}^{-1}$ of feed glycerol (Fig. 1a). 1,3-propanediol yield was not affected by increasing glycerol feed concentration and was always around $0.65 \mathrm{~mol}$ 1,3-propanediol $/ \mathrm{mol}$ glycerol consumed. Therefore, an improvement of volumetric productivity was observed with increasing dilution rate or glycerol feed concentration (Fig. 2). The highest volu- metric productivity value, $10.3 \mathrm{~g} \mathrm{l}^{-1} \mathrm{~h}^{-1}$, was obtained at a dilution rate of $0.30 \mathrm{~h}^{-1}$ with $60 \mathrm{~g} \mathrm{l}^{-1}$ of feed glycerol. Biomass concentration was also affected by glycerol feed concentration, since up to a two fold increase was achieved when substrate concentration was changed from 30 to 60 and $70 \mathrm{~g} \mathrm{l}^{-1}$ (Fig. 1b). For every glycerol feed concentration, a decrease of biomass concentration was associated with an increase of residual glycerol in fermentation broth.

For a $30 \mathrm{~g}^{-1}$ glycerol feed, acetate and butyrate concentrations were constant, although the dilution rate increased; furthermore, butyrate concentration was always higher than acetate concentration (Fig. 3). How- 
Fig. 2 Influence of glycerol feed concentration and dilution rate on 1,3-propanediol volumetric productivity in continuous $3266\left(\mathrm{pH} 6.5,35^{\circ} \mathrm{C}\right)$. Filled circle $30 \mathrm{~g} \mathrm{l}^{-1}$ of feed glycerol, filled square $60 \mathrm{~g}^{-1}$ of feed glycerol, inverted triangle $70 \mathrm{~g} \mathrm{l}^{-1}$ of feed glycerol. Vertical bars represent standard deviation values cultures of $C$. butyricum VPI

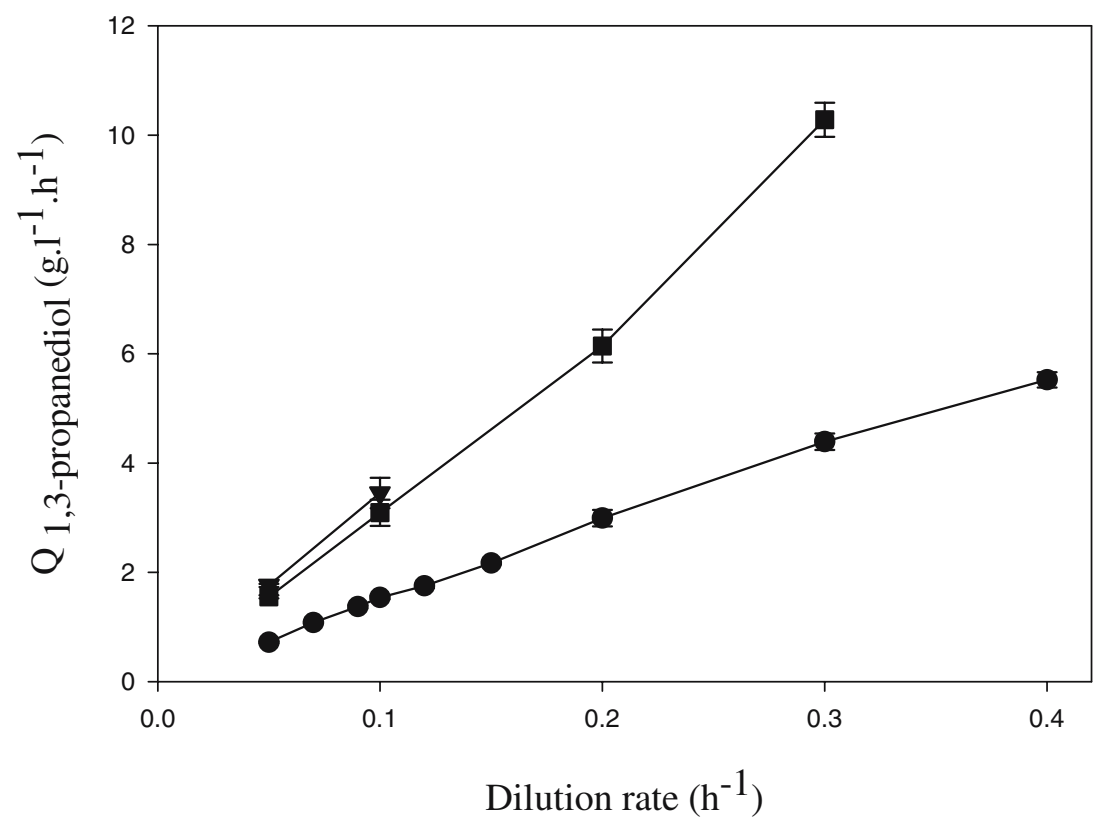

Fig. 3 Influence of glycerol feed concentration and dilution rate on acetate (solid symbols) and butyrate (open symbols) production in continuous cultures of $C$. butyricum VPI $3266\left(\mathrm{pH} 6.5,35^{\circ} \mathrm{C}\right)$. circle, filled circle $30 \mathrm{~g} \mathrm{l}^{-1}$ of feed glycerol; square, filled square $60 \mathrm{~g} \mathrm{l}^{-1}$ of feed glycerol.

Vertical bars represent standard deviation values

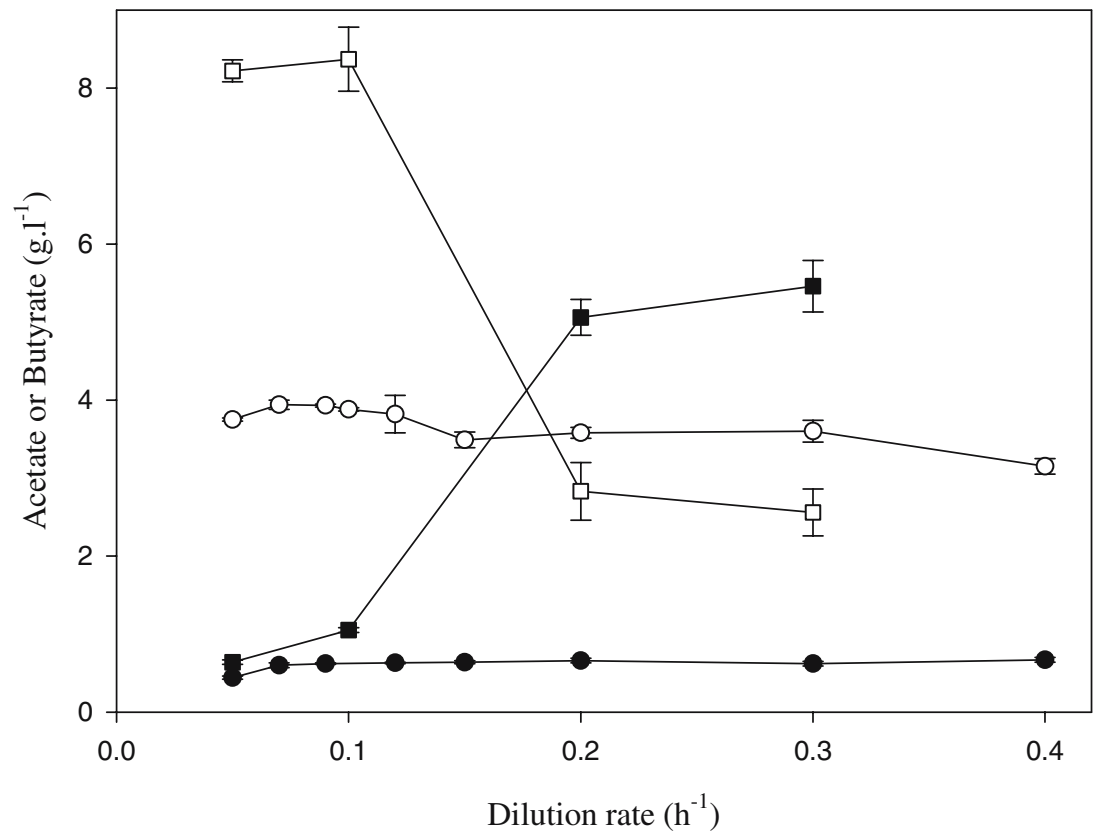

ever, a switch in the acetate/butyrate ratio occurred for a glycerol feed of $60 \mathrm{~g} \mathrm{l}^{-1}$, at dilution rates of 0.20 and $0.30 \mathrm{~h}^{-1}$, indicating a change in the metabolic carbon flux. At $D=0.30 \mathrm{~h}^{-1}, 3$-HPA was detected for the first time in the fermentation broth of C. butyricum, although quantification was not possible, as the pure compound was not available.

\section{Discussion}

Clostridium butyricum VPI 3266 has been described as the best candidate for 1,3-propanediol production, since it was demonstrated that this strain carries out a $\mathrm{B}_{12}$-vitamin independent process [13]. It has also been shown that this strain is able to produce $30 \mathrm{~g} \mathrm{l}^{-1}$ of 1,3-propanediol, with a molar yield of 0.61 , in continuous cultures using a synthetic medium and raw glycerol [4]. However, there are no reports in literature establishing high substrate consumption values for high growth rate continuous cultures, as pointed out by Biebl et al. [3]. In chemostat cultures with a feed glycerol concentration of $10 \mathrm{~g}^{-1}, C$. butyricum DSM 5431 could grow up to a maximum growth rate of $0.26 \mathrm{~h}^{-1}$, with exhaustive glycerol consumption [1]; biomass decreased markedly at $0.30 \mathrm{~h}^{-1}$, corresponding to glycerol accumulation. 
Klebsiella pneumoniae has also been considered a good 1,3-propanediol producer. Menzel et al. [9] showed that this microorganism was able to produce 35.2 $48.5 \mathrm{~g}^{-1}$ of 1,3-propanediol in continuous fermentation and volumetric productivities of $4.9-8.8 \mathrm{~g} \mathrm{l}^{-1} \mathrm{~h}^{-1}$ were obtained at dilution rates between 0.10 and $0.25 \mathrm{~h}^{-1}$; however, in these experiments more than $45 \mathrm{~g} \mathrm{l}^{-1}$ of residual glycerol were observed in the fermentation broth. Moreover, $K$. pneumoniae is an opportunist pathogen microorganism and special care must be taken when used in fermentation. In another attempt to increase the volumetric productivity, $C$. $b u$ tyricum DSM 5431 was cultivated in a cell recycle bioreactor with $55 \mathrm{~g} \mathrm{l}^{-1}$ of feed glycerol [12]. In this case, a 1,3-propanediol concentration of $26.5 \mathrm{~g} \mathrm{l}^{-1}$ was maintained up to a dilution rate of $0.50 \mathrm{~h}^{-1}$, which corresponds to a high volumetric productivity $\left(13.3 \mathrm{~g} \mathrm{l}^{-1} \mathrm{~h}^{-1}\right)$. Nevertheless, this process could only be run for short time periods as the microfiltration membrane was prone to clogging. Other bacteria genus have been used for 1,3propanediol production. Pflugmacher and Gottschalk [11] developed an immobilised cell reactor for 1,3-propanediol production by Citrobacter freundii. However, $10 \mathrm{~g} \mathrm{l}^{-1}$ of residual glycerol were observed and only $18.7 \mathrm{~g}^{-1}$ of 1,3 -propanediol were produced with $60 \mathrm{~g} \mathrm{l}^{-1}$ of feed glycerol and $D=0.30 \mathrm{~h}^{-1}$. These results lead to a relatively low 1,3 -propanediol yield $(0.46 \mathrm{~mol} /$ mol) and a poor productivity $\left(5.6 \mathrm{~g} \mathrm{l}^{-1} \mathrm{~h}^{-1}\right)$. Hartlep et al. [6] reported a two step-process for 1,3-propanediol production, wherein glucose was first converted to glycerol by a recombinant Escherichia coli strain; in a second stage, glycerol was converted to 1,3-propanediol by $K$. pneumoniae. A fed-batch cultivation under limiting glucose supply resulted in a production of $14 \mathrm{~g} \mathrm{l}^{-1}$ of 1,3-propanediol in the second stage, leading to a productivity of $2 \mathrm{~g}^{-1} \mathrm{~h}^{-1}$. The 1,3-propanediol productivity observed in the present work, $10.3 \mathrm{~g} \mathrm{l}^{-1} \mathrm{~h}^{-1}$, is the highest value reported for chemostat cultures.

The switch in acetate/butyrate ratio observed in this work was reported before for C. butyricum DSM 5431 growing in glycerol [1]: whereas at $\mathrm{D}$ values from 0.05 to $0.26 \mathrm{~h}^{-1}$ cells produced more butyrate than acetate, at a $\mathrm{D}$ value of $0.30 \mathrm{~h}^{-1}$ a switch was observed and the cells produced more acetate than butyrate. C. tyrobutyricum grown on glucose also showed a decrease of the selectivity for butyrate with an increase in glucose concentration [10]; this decrease was observed at both $D=0.10 \mathrm{~h}^{-1}$ and $D=0.20 \mathrm{~h}^{-1}$, but was faster at $D=0.20 \mathrm{~h}^{-1}$. Up to now, accumulation of 3-HPA, described as a toxic compound to the cells [1], was never reported for C. butyricum. In this work, 3-HPA was detected in fermentation broth from chemostat cultures with $60 \mathrm{~g} \mathrm{l}^{-1}$ of feed glycerol at a dilution rate of $0.30 \mathrm{~h}^{-1}$, when the acetate/butyrate ratio was higher than one. Formation of butyrate is redox-neutral, but acetate synthesis generates NADH excess, which could be used for the production of 1,3-propanediol from 3-HPA. The 1,3-propanediol yield observed in this case, $0.68 \mathrm{~mol} / \mathrm{mol}$, is very close to the theoretical maximum yield $(0.70 \mathrm{~mol} / \mathrm{mol})$ calculated by Zeng [18] in conditions of no butyrate and no $\mathrm{H}_{2}$ formation. The strain VPI 3266 is known to produce no molecular $\mathrm{H}_{2}$ when grown on glycerol as the sole carbon and energy source [14]. Therefore, the inversion of the acetate/butyrate rate may be a mechanism to avoid accumulation 3-HPA by increasing NADH availability.

In this work it was shown that C. butyricum VPI 3266 is able to produce up to $30 \mathrm{~g}^{-1}$ of 1,3-propanediol in continuous cultures from $60 \mathrm{~g}^{-1}$ of feed glycerol, at high dilution rate, leading to a volumetric productivity of $10.3 \mathrm{~g} \mathrm{l}^{-1} \mathrm{~h}^{-1}$. This value is the highest ever reported for a chemostat culture of $C$. butyricum. A constant propanediol yield, close to the theoretical value, was also obtained in this work, irrespective of substrate concentration or dilution rate. Since an economic production of 1,3-propanediol from glycerol requires high final concentration and productivity and considering that 1,3propanediol production by C. butyricum VPI 3266 is a $\mathrm{B}_{12}$-vitamin independent process, this strain seems to be the best natural candidate for a 1,3-propanediol industrial process.

Acknowledgements This work was financially supported by the European FAIR project (Contract No. FAIR-CT96-1912). M.González-Pajuelo was supported by PRAXIS XXI with a PhD grant $(\mathrm{BD} / 16036 / 98)$.

\section{References}

1. Abbad-Andaloussi S, Dürr C, Raval G, Petitdemange H (1996) Carbon and electron flow in Clostridium butyricum grown in chemostat culture on glycerol and glucose. Microbiology 142:1149-1158

2. Biebl H, Marten S, Hippe H, Deckwer W-D (1992) Glycerol conversion to 1,3-propanediol by newly isolated clostridia. Appl Microbiol Biotechnol 36:592-597

3. Biebl H, Menzel K, Zeng A-P, Deckwer W-D (1999) Microbial production of 1,3-propanediol. Appl Microbiol Biotechnol 52:289-297

4. González-Pajuelo M, Andrade JC, Vasconcelos I (2004) Production of 1,3-propanediol by Clostridium butyricum VPI 3266 using a synthetic medium and raw glycerol. J Ind Microbiol Biotechnol 31:442-446

5. Hall RH, Stern ES (1950) Acid-Catalysed hydration of acraldehyde. Kinetics of the reaction and isolation of $\beta$ - Hydroxypropaldehyde. J Chem Soc 1950:490-498

6. Hartlep M, Hussmann W, Prayitno N, Meynial-Salles I, Zeng AP (2002) Study of two-stage processes for the microbial production of 1,3-propanediol from glucose. Appl Microbiol Biotechnol 60:60-66

7. Heyndrickx M, de Vos P, Vancanneyt M, de Ley J (1991) The fermentation of glycerol by Clostridium butyricum LMG $1212 \mathrm{t}_{2}$ and $1213 \mathrm{t}_{1}$ and Clostridium pasteurianum LMG 3285. Appl Microbiol Biotechnol 34:637-642

8. Homann T, Tag C, Biebl H, Deckwer W-D, Schink B (1990) Fermentation of glycerol to 1,3-propanediol by Klebsiella and Citobacter strains. Appl Microbiol Biotechnol 33:121-126

9. Menzel K, Zeng A-P, Deckwer W-D (1997) High concentration and productivity of 1,3-propanediol from continuous fermentation of glycerol by Klebsiella pneumoniae. Enzyme Microbiol Technol 28:82-86

10. Michel-Savin D, Marchal R, Vandecasteele JP (1990) Butyrate production in continuous culture of Clostridium tyrobutyricum: 
effect of end-product inhibition. Appl Microbiol Biotechnol 33:127-131

11. Pflugmacher U, Gottschalk G (1994) Development of an immobilized cell reactor for the production of 1,3-propanediol by Citrobacter freundii. Appl Microbiol Biotechnol 41:313-316

12. Reimann A, Biebl H, Deckwer W-D (1998) Production of 1,3propanediol by Clostridium butyricum in continuous culture with cell recycle. Appl Microbiol Biotechnol 49:359-363

13. Saint-Amans S, Girbal L, Andrade J, Ahrens K, Soucaille P (2001) Regulation of carbon and electron flow in Clostridium butyricum VPI 3266 grown on glucose-glycerol mixtures. J Bacteriol 183:1748-1754

14. Saint-Amans S, Perlot P, Goma G, Soucaille P (1994) High production of 1,3-propanediol from glycerol by Clostridium butyricum in a simply controlled fed-batch system. Biotechnol Lett 17:211-216

15. Saint-Amans S, Soucaille P (1995) Carbon and electron flow in Clostridium butyricum VPI 3266 grown in chemostat culture on glucose-glycerol mixtures. Biotecnol Lett 17:211-216

16. Solobov M, Smiley KL (1960) Metabolism of glycerol by an acrolein-forming lactobacillus. J Bacteriol 79:261-266

17. Vasconcelos I, Girbal L, Soucaille P (1994) Regulation of carbon and electron flow in Clostridium acetobutylicum grown in chemostat culture at neutral $\mathrm{pH}$ on mixtures of glucose and glycerol. J Bacteriol 176:1443-1450

18. Zeng A-P (1996) Pathway and kinetic analysis of 1,3-propanediol production from glycerol fermentation by Clostridium butyricum. Bioprocess Eng 14:169-175 